\title{
Narrating Past to Present: Conveying the Needs and Values of Older People to Young Digital Technology Designers
}

\author{
Elizabeth Valentine ${ }^{1}$, Ania Bobrowicz ${ }^{1}$, Graeme Coleman ${ }^{2}$, Lorna Gibson ${ }^{2}$, \\ Vicki L. Hanson ${ }^{2}$, Saikat Kundu ${ }^{3}$, Alison $\mathrm{McKay}^{3}$, and Raymond Holt ${ }^{3}$ \\ ${ }^{1}$ School of Engineering and Digital Arts, University of Kent \\ Canterbury, CT2 7NT, UK \\ ${ }^{2}$ School of Computing, University of Dundee \\ Dundee, DD1 4HN, UK \\ ${ }^{3}$ School of Mechanical Engineering, University of Leeds \\ Leeds, LS2 9JT, UK \\ elizabeth.valentine@bbc.co.uk, a.bobrowicz@kent.ac.uk, \\ \{gcoleman, lgibson, vlh\} acomputing.dundee.ac.uk, \\ \{s.kundu, a.mckay,r.j.holt\}@leeds.ac.uk
}

\begin{abstract}
In this paper we discuss preliminary findings from the first stage of our SEEDS study (SEEDS: An Organic Approach to Virtual Participatory Design), a collaborative research project between Universities of Dundee, Kent and Leeds, United Kingdom. This feasibility study investigates how to motivate older people to engage with digital technology, as well as how to improve understanding of older people's needs and requirements amongst young designers. As part of this study we recorded interviews with older people which investigated their motivations to use or not use digital technologies and themes pertaining to their (dis)engagement. A virtual repository was created to make collected interviews, which were presented as social stories, available to engineering, technology and design students. In this paper we discuss the findings from a prototyping exercise with undergraduate and postgraduate students which took place in stage one at the Universities of Kent and Leeds.
\end{abstract}

Keywords: design, older people, young designers, motivation, inclusion, education.

\section{Introduction}

Digital technologies pervade many aspects of modern life; benefiting large proportions of society; enabling people to shop, work, relax, stay healthy and communicate in increasingly convenient, cost-effective and rich ways. However, not everybody engages with digital technologies such as the Internet, creating a digital divide [1]. The Economic Case for Digital Inclusion, which highlights the links between social and digital exclusion [2] identifies 10.2 million UK citizens as being digitally disengaged (having never accessed the Internet), with the largest group, comprising $62 \%$ of 
the total, of people over 65. This age group is growing in both numbers and wealth [3] [4]; it is attractive to capture their interest in digital products and services. However, merely enabling people to physically connect to the Internet may not, by itself, be sufficient, as it may not make the technology appear any more relevant or worthwhile to those who already do not use it.

In order to both learn what encourages older people to become digitally connected, what dissuades them, and what can encourage young designers to consider these needs and desires, the SEEDS research project investigated methods of involving older people in the design process. We considered mediated intergenerational methods, using virtual frameworks to present social stories captured from one generation to another. We report upon this process in this paper.

\subsection{Older People and Technology}

It may be argued that older people are less likely to use digital technologies due to lack of previous exposure, and that this will decrease over time, yet we propose that there are additional issues that result in a lack of use amongst older people; peeropinion, cost and maintenance, previous negative experiences, lack of understanding and fundamentally a lack of perceived need [5]. In our research the theme of digital technologies as being for "others", "clever" or "younger" people and not aimed at the older self is oft heard. Such technologies may seem to be both irrelevant and problematic, a negative or neutral influence that results in disengagement.

Older people are a wide and diverse group, associated by only their physical age; individuals may not hold the same values as another and each person's abilities, motivations and understandings can differ widely. Thus, not all older people have the same relationship with digital technology. Older embracers of digital technology vary from those who gain much publicity due to their age and relatively prolific web presence (e.g. geriatric1927 on YouTube [6], and the late ivybean104 on Twitter [7]), to those who wish to communicate, shop and bank online, or simply use the Internet as an information tool. People who do not engage also vary, from those who refuse to participate, to those who simply don't feel the need for digital technologies or are dissuaded by various factors [5].

\subsection{Designing for the Young Generation}

Digital products and services are primarily designed by and for younger people, who may find it hard to imagine life without them. Few do not use the Internet or own a mobile phone, which are designed and advertised as facilitating the lives of busy, sociable people, requiring good eyesight and agile fingers to use them successfully. Products aimed at older people may be limited, simplified adaptations of the mainstream product, with large buttons and poor aesthetics, advertised in specialised catalogues. Downgraded features mean that older people may feel stigmatised; the digital products aimed at them are not something that others would wish to use. Designers can tend to create interfaces for homogenous groups of people, for example a "design for older people" whereas this group is very diverse. 


\subsection{Bridging the Gap between Young and Old}

We propose that this misalignment between what older people may wish to use and what they are marketed is due to a lack of understanding of and empathy with their wants, needs and values at the outset of the design process. Instead of considering these factors as a starting point for design (as one may do when designing for people like oneself), designers tend to redesign and adapt existing products and services into lesser versions, best considering a single physical impairment (e.g. reduced vision and digit dexterity), rather than lifestyles and values. Experiential and cultural gaps also exist between younger and older people, thus communicating ideas that involve technological jargon between parties can be difficult, leading to a situation where designs are based upon the developer's interpretations of an older person's needs , "a solution that can be ineffective and patronising" [8]. As the natural relationships between these generations have become progressively disconnected from each other at an individual, family and community level [9], there is an urgent need to educate young designers about the needs and values of older people.

SEEDS originated against a background of intergenerational activities [10] [11] [12] which aim to foster understanding between older and younger people.

\section{Background to SEEDS}

Our project is a collaborative research study between the universities of Dundee, Kent and Leeds, funded by the Engineering and Physical Sciences Research Council (EPSRC) UK. It is concerned, among other things, with how might the disengaged older people, young designers, and other interested parties be brought together to create solutions that address the needs of individuals.

\section{Design Projects}

The aim of our feasibility study is to establish a design methodology which can be used to bring the voices of individual older users, from digitally disengaged communities, into the very early stages of a design activity, before solutions have been explored or proposed. Another consideration is to build the developed methodology into the educational curriculum available to technology designers.

To that effect, we recorded 29 audio interviews with older people in the form of social stories; 14 at Kent and 9 at Dundee, with digitally disengaged people, and 6 at Leeds with those who had recently started learning IT. The digitized stories were uploaded to a repository in a protected on-line community. They were subsequently made available to groups of students on the undergraduate multimedia technology and design degree at Kent and a postgraduate engineering design degree at the University of Leeds. Our aim was find out whether or not access to such social stories would enhance the understanding of older people's needs among young designers and result in better design solutions. 


\subsection{University of Kent}

At the University of Kent, the SEEDS project was integrated into an optional module entitled Digital Culture which was taken by 48 final year multimedia technology and design students in 2010. This multidisciplinary degree is strongly technology-focused and encompasses a wide variety of modules, from visual communication and interaction design to software engineering, animation and film-making. An important part of the degree involves imparting the knowledge of user-centred design to young digital technology designers. All 48 students were given the same design brief: a) to read recommended literature in order to understand the issues relating to design for the older people; and b) to propose a suitable design solution which would motivate older people to engage with digital technology. The cohort was divided into two groups. One group was given access to papers and two interviews from the online repository (each team had a different pair of interviews detailing older people's pastimes, lifestyles and access/or not to digital technology), while the other group did not have access to the interviews. Within each group, students worked in teams of three and four.

Discussion of the findings. Our findings are based on the analysis of 13 team reports as well as discussions with teams in seminars with a view of identifying a change in perception of older people as a result of accessing the social stories. Our findings include a summary of positive outcomes as well as lessons learnt.

1. Positive outcomes from the social stories group

- Out of six teams who had access to the audio interviews, all but one referred to interviews when discussing their design process.

- Three teams went further than simply referring to papers and interviews and talked to their grandparents with a view of getting some further insight into their lives and their interest in digital technology.

- Listening to social stories brought older people's lives closer to students, thus making them more personable and easier to relate to. Most teams referred to 'an older person from audio interviews', while discussing their needs and lifestyles.

- In two projects, design solutions were directly inspired by stories older people told - favourite pastime (library) and favourite place at home (fireplace).

- Although this group referred to literature, the interviews were mentioned more often than papers.

2. Lessons learnt from the group with no access to social stories

- The group with no access to the social stories wished they had been given access to them.

- Two teams used their own initiative and interviewed older people they knew. This was due to a perception among some students that not having access to stories will somehow adversely affect their marks. As a result, one of the teams came up with a very innovative design solution based directly on the interview they took (SEED pod project).

- The group's referencing of literature was rather mixed. Two teams seem to have referred more extensively to published papers and reports than other students in either group. Others teams' references were more sketchy. The difference seems to 
have been dependent upon the academic strengths of individual teams, rather than access or not to social stories.

\subsection{University of Leeds}

At the University of Leeds the study was conducted with five postgraduate (MDes.) product design students in their team design project. The students were given access to six audio recorded interviews with older adults about their personal stories. The stories included daily and working lives, interests and pastimes, contact with and use of technology (at home and in public places), views on digital technology. The design methodology was based on the Systems Engineering ' $\mathrm{V}$ ' model and the spiral iterative product design model. For a detailed account see [13]. Initially, the students listened to the interviews (archived in a virtual repository) and created their summaries highlighting issues experienced by older adults in daily lives or routines. In this way they gained insights into the needs of older adults as potential users of digital technologies. Afterwards, the students carried out review of literature. Next, the student designers proposed a number of initial design concepts in response to the stories. Low fidelity prototypes of initial design concepts were created to aid in user evaluation. The student designers carried out evaluations of the initial design concepts (through interviews and discussions) with representative older adults (at local Age Concern office) by reviewing prototypes and obtaining user feedback. Originally, it was intended to evaluate the design work with the original interviewees but practical difficulties such as the time taken to generate the designs made review with the original interviewees infeasible. From the user feedback, the student designers produced an updated and detailed definition of design requirements and technical design specifications to inform final design solutions. Final design solutions were produced to meet the needs, wants and aspirations of older adults (examples of the final design solutions are available online at: www.leeds.ac.uk/productdesign/showcase/ proddesignv3/index.htm\#/118/) and high fidelity prototypes created to aid in user testing.

\subsubsection{Discussion of the findings}

The findings at Leeds were as follows:

- Initial feedback from student designers indicated that the interviews gave fresh perspectives on designing for older adults. The interviews, used as part of a virtual participatory design approach, provided designers with fast access to more users than would have been possible using traditional participatory design. Interviews captured as social stories in virtual repository reduces time and effort needed from the users themselves.

- In addition, the interviews (captured as social stories) inspired the students to carry out the same style of research with their own focus groups. For example, some students used their own initiative and interviewed their older relatives and their parents and grandparents to gain further insights into the needs and aspirations of older adults.

- Students' attitudes towards the older adults seemed to change through the team design project, evidenced, for example, by the language they used to refer to their users. It is not ascertained whether this change of attitudes of student designers 
was as a result of listening to the individual stories (interviews) of older adults, or meeting older adults (while evaluating initial design concepts) or something else. However, it could largely be due to the former two reasons.

- At the end of the project, there was a real benefit in the students being able to evaluate their actual designs with real users. We observed that feedback from the real users made a significant improvement to the detailed definition of design requirements, technical design specifications and the final design solutions.

\section{Lessons learnt}

These experiences led to the conclusion that the personal stories of older adults enhance inspirations among young designers to better understand and gather more information about older people's needs early in a design process.

\section{Conclusion}

This paper has considered the findings from a prototyping exercise with undergraduate and postgraduate students which took place in stage one of the SEEDS project at the Universities of Kent and Leeds. The results from the studies indicate that access to social stories for both undergraduate and postgraduate students inspired them to carry out more research into this user group. Some students used their own initiative and interviewed their older relatives and their parents and grandparents to gain further insights into the needs and aspirations of older adults. Students' attitudes towards the older adults seemed to indicate that access to social stories has brought people's needs and lives closer to the young designers. This was evidenced, for example, by the language they used to refer to their users (Leeds), and references to people's lives, favourite objects and pastimes (Kent). Our initial findings indicate that providing young designers with access to rich lived experiences of older people may result not only in changed perceptions, but also in designs inspired directly by older people's lives.

Acknowledgements. This paper reports on research funded by an Engineering and Physical Sciences Research Council grant (EP/H006834/1) as part of the 'Design for Digital Economy' Programme.

\section{References}

1. Agarwal, R., Animesh, A., Prasad, K.: Social Interactions and the "Digital Divide": Explaining Variations in Internet Use. Information Systems Research 20(2), 277-294 (2009)

2. PricewaterhouseCoopers (PwC): Champion for Digital Inclusion: The Economic Case for Digital Inclusion (2009)

3. Ageing Fastest increase in the 'oldest old', Office of National Statistics (June 2010), http: / / www.statistics.gov.uk/cci/nugget.asp? ID=949

4. Newell, A.: HCI and Older People. HCI and the Older Population. In: BCS HCI 2004, Leeds, UK (2004) 
5. Kundu, S., McKay, A., Holt, R., Valentine, E., Bobrowicz, A., Coleman, G., Gibson, L., Hanson, V.: Towards an Organic Participatory Approach to Design for Digital Inclusion. In: Chakrabarti, A. (ed.) Research into Design: Supporting Sustainable Product Development, Proceedings of the 3rd International Conference on Research into Design (ICoRD 2011). Indian Institute of Science, Bangalore, India, January 10-12, pp. 220-227. Research Publishing, Singapore (2011)

6. geriatric1927, http://www.youtube.com/user/geriatric1927 (accessed January 23, 2011)

7. “ivybean104", Ivy Bean, Twitter page, http://twitter.com/ivybean104 (accessed January 23, 2011)

8. Gregor, P., Newell, A.F.: Designing for dynamic diversity - making accessible interfaces for older people. In: ACM, Jorge, J., Heller, R., Guedj, R. (eds.) Proceedings of WUAUC 2001 (2001 EC/NSF Workshop on Universal Accessibility of Ubiquitous Computing: Providing for the Elderly, Portugal, May 22-25 (2001)

9. Building Better Communities for All Ages, Centre for Intergenerational Practice, http: / /www. centreforip.org.uk/

10. Newell, A.F., Gregor, P.: User sensitive inclusive design: In search of a new paradigm. In: Proceedings on the 2000 Conference on Universal Usability (CUU 2000), pp. 39-44. ACM, New York (2000)

11. Centre for Intergenerational Practice, http: / /www . centreforip.org.uk/

12. Cambridge Interdisciplinary Research Centre on Ageing, http: / / www.circa.co.uk/

13. The Royal College of Art Helen Hamlyn Research Centre, http: / /www.hhc.rca.ac.uk/193/all/1/about-us.aspx

14. Critchfield, F., Huggins, C., Harrison-Stanton, M., Jain, S., Pattinson, L.: Delivering Digital Inclusion: An Exploration to Solve the Digital Exclusion of Older Adults through User Participatory Design Iterations) (2010), http: / / www.engineering. leeds.ac.uk/ e-engineering/documents/Critchfield_Pattinson_et_al.pdf 